\title{
Institucionalização das indicações geográficas no Brasil e na Espanha
}

\author{
Institutionalization of geographical indications in Brazil and Spain
}

\author{
Fernanda Novo da Silva ${ }^{\mathrm{I}}$ Flávio Sacco dos Anjos ${ }^{\mathrm{I}{ }^{*}}$ Nádia Velleda Caldas $^{\mathrm{II}}$ \\ Germano Ehlert Pollnow ${ }^{\mathrm{III}}$
}

RESUMO

O artigo analisa os desafios existentes, no Brasil, com relação à institucionalização das indicações geográficas de produtos agroalimentares, tomando por base a experiência europeia. A recente expansão no número de experiências de diferenciação não tem sido capaz de engendrar mudanças requeridas para estabilizar um sistema que, atualmente, mostra-se extremamente frágil e carente de coordenação. O estudo baseiase numa abordagem comparativa entre o marco legal brasileiro e europeu, considerando a existência de diversas experiências de indicações geográficas da Espanha (Andaluzia) e do Rio Grande do Sul (Serra Gaúcha).

Palavras-chave: indicações geográficas, Brasil, Espanha, processos de institucionalização.

\section{ABSTRACT}

The paper examines the challenges that exist in Brazil, with respect to the institutionalization of geographical indications of agricultural food products, based on the European experience. The recent expansion in the number of experiences of differentiation has not been able to engender changes required to stabilize a system that currently shows up extremely fragile and lacking coordination. The study is based on a comparative approach between the Brazilian and European legal framework considering the existence of diverse experiences of geographical indications of Spain (Andalusia) and Rio Grande do Sul (Serra Gaucha).

Key words: geographical indications, Brazil, Spain, institutionalization processes.

\section{INTRODUÇÃO}

Durante muito tempo, admitiu-se que o combate às falsificações seria uma condição necessária e suficiente para justificar o surgimento das indicações geográficas (doravante referidas como IG) na produção agroalimentar do velho mundo, sobretudo no caso da produção vitivinícola. No presente trabalho, trataremos de mostrar que a realidade atual ultrapassa os limites desse entendimento. Antes, porém, convém sopesar alguns aspectos.

O caso do Vinho do Porto é emblemático para introduzir a discussão que enseja o presente trabalho. A produção de vinhos, na região do Douro, segundo registros arqueológicos, remonta ao século III. Transportado pelos famosos barcos rabelos, o precioso líquido chegava aos entrepostos da cidade do Porto para sofrer a adição de aguardente e açúcar antes de ser finalmente exportado à Inglaterra. Foi pela mão do Marquês de Pombal que ocorreram as grandes transformações que culminaram, em 1756, com a criação da Companhia Geral de Agricultura das Vinhas do Alto Douro, cujos objetivos eram: assegurar a qualidade do produto, evitar adulterações, regular a produção e o comércio do produto e estabilizar os preços praticados à época. São esses os aspectos que resumidamente aparecem associados ao surgimento, em termos históricos, da primeira iniciativa de delimitação da área de produção, materializada na instalação de marcos de pedra que indicavam as áreas mais adequadas para a produção vinícola, bem como do cadastro dos produtores. Existe amplo consenso de que o caso em tela, que conecta duas regiões distintas da geografia lusitana (Douro e Porto), representa, em

\footnotetext{
IPrograma de Pós-graduação em Sistemas de Produção Agrícola Familiar, Universidade Federal de Pelotas (UFPel), Pelotas, RS, Brasil.

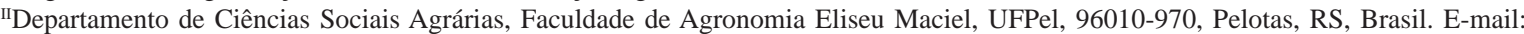
saccodosanjos@gmail.com.*Autor para correspondência.

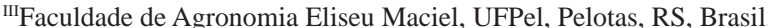


última análise, a primeira experiência mundial de indicação geográfica protegida.

Assim, se o tema das falsificações sempre esteve presente no mundo da vinicultura, também é certo afirmar que a falta de organização dos produtores há que ser apontada como "meio de cultura” propício para que proliferassem os problemas e prejuízos para o setor. Sobre esse aspecto, cabe aqui relatar um outro exemplo. Se, na região nordeste sul-riograndense (vulgarmente conhecida como Serra Gaúcha), a introdução das videiras aparece inextricavelmente ligada à imigração italiana, iniciada em 1875, no extremo sul gaúcho, mais precisamente na Serra dos Tapes, a aparição dessa cultura se deve ao surgimento da colônia francesa (zona rural de Pelotas), em 1880.

Tratava-se de uma das mais promissoras experiências de colonização no Brasil meridional, onde o vinho, artesanalmente produzido em pequenas cantinas familiares, era comercializado na cidade de Pelotas e região, valendo-se de "bacelos de uvas americanas, pois as castas europeias [sic] estavam empobrecidas no território do Rio Grande do Sul” (GRANDO, 1990:86). Já no começo do século XX, com o crescimento na importância dessa atividade produtiva e do número de cantinas, medidas mais avançadas foram adotadas, como no caso da criação, em 1890, da cadeira de vitivinicultura e ecologia no então "Liceu Riograndense de Agronomia e Veterinária de Pelotas”, da distribuição de novas castas apropriadas para a produção de vinho por parte da "Sociedade Agrícola e Pastoril do Rio Grande”, assim como da primeira exposição agrícola do Rio Grande do Sul, onde foram expostos mais de 30 qualidades de vinhos produzidos em Pelotas (GRANDO, 1990:87). Lamentavelmente, a experiência da vitivinicultura pelotense só faz confirmar a assertiva com que introduzimos este artigo. Valemo-nos das observações de Grando para explicitar a trajetória declinante daquelas cantinas. Segundo suas próprias palavras:

Completamente à margem do processo de industrialização que estava em marcha no setor, os vitivinicultores pelotenses mantiveram-se também isolados entre si, pois não foram criadas, localmente, formas de associação de capitais em torno da vinicultura. As cantinas permaneciam rudimentares [...] (GRANDO, 1990:90).

O ocaso da produção vitivinícola pelotense coincide com o avanço da indústria vinícola na encosta superior sul-riograndense que, paulatinamente, introduz mecanismos de controle da produção, aperfeiçoa métodos de cultivo e incrementa a produtividade dos parreirais. Se o exemplo do vinho do Porto serve como marco referencial para entender o modo através do qual foram lançadas as bases para o surgimento de sofisticados mecanismos de controle da qualidade da produção oriunda de uma das mais clássicas zonas produtoras de uvas do planeta, o caso dos vinhos pelotenses só faz confirmar a premissa com que iniciamos essa reflexão. Com isso, o que se quer aqui destacar é que não foi por obra do acaso o surgimento da primeira experiência de Indicação Geográfica do Brasil justamente no interior da Serra Gaúcha (Vale dos Vinhedos), a qual é vista hoje como marco referencial para a aparição de todas iniciativas subsequentes dessa ordem em distintos rincões da geografia nacional. Todavia, a qualidade, no âmbito agroalimentar, é um conceito deveras amplo, um atributo difícil de ser definido, e no qual entram em jogo diversos aspectos. Essa discussão, ainda que pertinente, transcende o objeto central do presente trabalho. Parte-se aqui do entendimento de que as IG representam apenas uma das facetas através das quais é possível decifrar as grandes transformações que atualmente atravessam o mundo da alimentação, em toda sua abrangência e complexidade.

Nesse sentido, caberia indagar: como se apresenta a evolução desse tipo de dispositivo de diferenciação e de qualidade em nosso país em relação a outras experiências internacionais? Dispomos, atualmente, de um marco institucional que nos permita avançar no aperfeiçoamento desses processos e, consequentemente, do ponto de vista da ampliação de perspectivas para a produção agroalimentar no acesso aos mercados mais exigentes? Em linhas gerais, são essas as grandes questões que embasam a reflexão aqui proposta.

\section{MATERIAL E MÉTODOS}

Este estudo baseia-se nos dados e informações coletados no marco de um projeto de cooperação e intercâmbio (Acordo Capes DGU) que integra a Universidade Federal de Pelotas, a Universidade Federal de Santa Maria e a Universidade de Sevilha (Espanha) sobre o tema das indicações geográficas de produtos agroalimentares. Desenvolvido entre os anos 2009 e 2012, a presente pesquisa realizou diversas entrevistas com vitivinicultores e olivicultores da Andaluzia, Serra Gaúcha (RS), membros de Conselhos Reguladores, agentes de desenvolvimento rural, pesquisadores, agricultores, técnicos de empresas de certificação e outros atores sociais ligados a experiências de IG e marcas coletivas de qualidade, as quais não serão analisadas neste trabalho, que se apóia, 
fundamentalmente, numa abordagem eminentemente comparativa entre o marco legal e institucional das indicações geográficas do Brasil e da Europa.

Consumo, distinção e produção agroalimentar Durante décadas, o tecido social e produtivo que congregava produtores, transformadores, distribuidores e consumidores em torno do que comemos e bebemos ocupou um lugar secundário nas preocupações sociais. Esse fato traduzia a progressiva redução da parte da renda destinada pelas famílias à aquisição de produtos alimentícios como resultado do crescimento na oferta de produtos agrícolas para o conjunto da população. Nesse contexto, os grandes escândalos agroalimentares (crise das dioxinas, doença das vacas loucas, gripe aviária e suína, febre aftosa, transgênicos e, mais recentemente, a crise dos pepinos espanhóis) representam a ponta de um grande iceberg que afeta o «mundo da alimentação», em toda sua complexidade. Dentro das grandes cadeias que configuram os sistemas agroalimentares, a crescente desvinculação entre produto agrário e produto alimentício (LANGREO NAVARRO, 1988), o deslocamento do centro de decisões do âmbito dos produtores para o de transformadores e, mais recentemente, para o dos distribuidores, produziram consequências importantes sobre as possibilidades de desenvolvimento das zonas rurais. A expansão dos monocultivos (soja, cana de açúcar, café, biocombustíveis, etc.) representa a face mais visível da destruição de saberes relacionados com a geração de alimentos no âmbito local e das sérias ameaças à diversidade de cultivos e criações no âmbito dos territórios.

Mas se trata de uma realidade paradoxal se temos em mente que são cada vez mais frequentes as iniciativas baseadas na geração de produtos de qualidade e com forte apelo à diferenciação, tanto no âmbito dos países desenvolvidos quanto no contexto dos países em desenvolvimento. Trata-se de estratégias que refletem duas possibilidades de êxito. Uma delas recai na perspectiva interna, envolvendo as dinâmicas sociais, culturais e econômicas dos atores sociais implicados e sua relação com o tecido institucional. A perspectiva externa refere-se aos significados dessa qualidade que os produtores rurais e as indústrias locais tratam de imprimir aos seus produtos e de que maneira tais atributos serão efetivamente percebidos ou assimilados pelos consumidores.

Desse modo, o rumo das estratégias que os atores locais põem em prática depende do modo como os consumidores avaliam a qualidade e a singularidade desses produtos e das formas através das quais são tecidas essas narrativas. Por outra parte, a viabilidade dessas estratégias depende, essencialmente, das representações sociais, construídas a partir da informação veiculada e do nível de conhecimento das pessoas em relação aos processos de elaboração.

Não nos esqueçamos da capacidade que qualquer objeto possui para evocar percepções, cujo ato de consumo produz não somente uma apropriação tangível deste, mas, sobretudo, distintos tipos de sensações (emocionais, comunicativas, valorativas, etc.). São esses os fundamentos que hoje orientam uma nova corrente de pensamento conhecida como Marketing Experiencial (SCHMITT, 1999). Trata-se de estratégia mercantil, que aposta por um último tratamento do produto e sua imediata conversão em objeto da experiência com um alto valor agregado. Nesse sentido, indagamo-nos: existem adjetivos suficientes para descrever o ato de saborear um vinho La Rioja em meio ao inebriante cenário da planície Alavesa? Parece lógico supor que cada vez que abrimos uma nova garrafa desse precioso líquido, a milhas de distância dessa região, voltamos ao lugar da primeira experiência e às sensações que experimentamos. E retornaremos ao mesmo cenário, ainda que virtualmente, porque não consumimos apenas um fermentado de uvas, mas uma paisagem e um conjunto de emoções que seguirão vivas, em nossas mentes, ao longo do tempo.

Por outro lado, assumimos como válida a existência de um conjunto de evidências que destacam a crescente invisibilidade dos sistemas agroalimentares, cujas características são cada vez mais abstratas (HERVIEU, 1996), como resultado da crescente intervenção sobre os alimentos e da modificação de seus traços característicos (forma, cor, sabor, textura). Um sistema que assume a forma de uma “caixa negra” (CONTRERAS, 2002) como um mecanismo de abastecimento de produtos cada vez mais industrializado, cuja origem e processos de obtenção são invisíveis aos olhos dos consumidores, que apenas conhecem os produtos finais e lugares de distribuição. Esse não é precisamente o caso das IG, como a seguir discutiremos.

Frente ao processo de padronização de alimentos, os consumidores começam a demandar alimentos "localizados" (MUCHNIK, 2006), ou seja, aqueles que incorporam valores específicos associados a um território, uma natureza, uma tradição e a um saber-fazer, dado que são vistos como mais "naturais", seguros e de maior qualidade (NYGARD \& STORSTAD, 1998). O mais significativo desse cenário é que tal interesse não se limita ao produto em si, estando muitas vezes associado à busca de 
novos modos de aquisição desses produtos sob a forma de um contato mais personalizado e direto com o produtor e, por extensão, com o território onde tais artigos foram produzidos (LOZANO, 2009).

Esses novos sentidos da qualidade estão associados à implementação de certas estratégias de diferenciação (Indicações de Procedência, Denominações de Origem) e à aparição de diversos movimentos e redes agroalimentares alternativas (Feiras de produtores, Cooperativas de consumidores, Comércio Justo e Solidário, Movimento Slow Food, etc.), cujos objetivos são: tornar visíveis os diferentes processos e agentes que sustentam uma cadeia produtiva, recompor as relações entre esses atores sociais, reduzir o protagonismo exagerado das grandes cadeias de distribuição, criar novos vínculos entre produtores e consumidores e promover modelos agroalimentares mais sustentáveis (DÍAZ et al., 2009).

Diferentemente do que ocorre nos países europeus, tal processo tem sido implantado no Brasil de forma bastante localizada. Rio Grande do Sul é um dos estados que concentra o maior número de IG do país, havendo algumas experiências relevantes, como a Indicação de Procedência do Vale dos Vinhedos (a primeira IG reconhecida pelo Instituto Nacional de Propriedade Intelectual - INPI) ou da primeira denominação de origem brasileira (Arroz Litoral Norte). O leque de experiências de diferenciação de produtos agroalimentares inclui também iniciativas de marcas coletivas e de sinais distintivos, a exemplo do "Cordeiro Herval Premium” ou do arroz orgânico “Amigo do Taim”, ambas situadas em localidades do extremo sul gaúcho (Herval e Santa Vitória do Palmar, respectivamente).

O fato é que há um sentido recorrente quando examinamos essas dinâmicas de diferenciação, à luz da respectiva trajetória que acompanha sua emergência, cuja ênfase recai na tentativa de evidenciar singularidades e atributos (tangíveis e intangíveis). Referimo-nos, objetivamente, ao modo como os consumidores avaliam as singularidades que tais artigos são presumivelmente portadores e as razões que influenciam a decisão de adquiri-los.

O que aqui se quer destacar é que paralelamente ao domínio da padronização do consumo agroalimentar, impulsionado pela globalização dos mercados através das grandes cadeias de distribuição, há também um movimento de extrema relevância e que aponta, ao fim e ao cabo, para uma direção diametralmente oposta.

Em resumidas contas, podemos dizer que o último decênio esteve marcado pela crise do padrão da quantidade (HERVIEU, 1996) e sua paulatina substituição por um novo modelo no qual a qualidade dos produtos e processos converte-se na tônica dominante. De outro modo, podemos dizer que o aludido período esteve associado à substituição de uma economia de volume por uma economia de valor, mediante a geração de produtos intensivos em conhecimentos (AGUILAR et al., 2003:177). Guardadas as devidas proporções, esse fenômeno atinge também o Brasil e o novo mundo em geral. As IG, como a seguir analisaremos, não podem ser vistas de forma desarticulada desse movimento geral, que prima pela qualidade, tipicidade e diferenciação.

\section{As indicações geográficas no Brasil}

O marco legal das IG do Brasil (Lei 9279 de 14/05/1996) é bastante recente e contempla somente duas figuras de proteção, quais sejam, as Indicações de Procedência (IP) e as Denominações de Origem (DO). A IP se refere ao nome geográfico do país, cidade, região ou localidade de seu território, a qual se tornou conhecida como centro de extração, produção ou fabrico de um determinado produto, ou pela prestação de um determinado serviço. A $\mathrm{DO}$, por seu turno, indica o nome geográfico de um país, cidade, região ou localidade de um território e que designa o produto ou serviço, cujas qualidades se devem exclusiva ou essencialmente ao meio geográfico, incluindo os fatores naturais e humanos.

A distinção entre ambas as figuras está no fato de que, no caso da IP, o relevante é a notoriedade associada à qualidade que alcançou um determinado produto ou serviço, ao passo que, no caso da DO, a excelência de um ou de outro deve estar ancorada, obrigatoriamente, nos aspectos físicos (solo, água, clima), humanos e culturais do meio onde houve o processo de obtenção ou produção. Tanto a IP quanto da DO devem ter seus respectivos registros no Instituto Nacional de Propriedade Industrial do Brasil (INPI).

Até o ano de 2010, havia apenas seis (6) Indicações Geográficas reconhecidas pelo INPI. Surgida em 2002, a IP dos vinhos finos e espumantes do Vale dos Vinhedos corresponde à primeira delas, seguida do café do Cerrado (2005), da carne bovina e derivados do Pampa Gaúcho da CAMPANHA MERIDIONAL (2006), cachaça de PARATY (2007) e couro curtido do Vale dos Sinos (2009).

Não obstante, os dados da figura 1 não deixam dúvidas acerca do vertiginoso incremento no número de IG brasileiras, o qual foi multiplicado 4,7 vezes no espaço de tempo correspondente aos últimos dois anos, e que, até o momento de elaboração deste artigo, compreendia 21 IP e sete DO (28 IG no total). 
Mas se, no caso da Europa, esse tipo de dispositivo de diferenciação, regulado atualmente pelo Regulamento CE 2081/92 (relativo às denominações de origem protegidas e indicações geográficas protegidas) e 2082/92 (relativo à certificação de características específicas ou especialidades tradicionais garantidas), contempla, exclusivamente, produtos agroalimentares (oriundos da transformação agroindustrial ou in natura), no caso brasileiro, há uma plêiade de artigos, incluindo calçados, pedras, mármores, que, em última análise, não guardam relação alguma com o mundo da alimentação e/ou da produção agropecuária.

Esse fato nos mostra que, ao pensar em IG, no Brasil e no velho continente, podemos estar referindo-nos a coisas absolutamente distintas. No âmbito europeu, para que um artigo leve a indicação DOP (Denominação de Origem Protegida), todas as fases de produção (obtenção das matérias-primas, transformação, maturação, elaboração final) devem realizar-se dentro de uma zona delimitada, sendo que as características do produto dependem exclusiva, ou essencialmente, de sua origem geográfica. Já no caso da IGP (Indicação Geográfica Protegida), ao menos uma das citadas fases da produção deve realizarse dentro de um determinado território, sendo que o vínculo com ele deve estar justificado pelo fato de estar relacionado a uma qualidade específica, reputação ou outra característica do produto.

No caso brasileiro, como aludimos anteriormente, a DO requer uma prova cabal da existência de atributos físicos do território que confiram a singularidade. Mas há ainda outras diferenças entre o marco europeu que serão mencionadas na próxima seção do artigo.
Outro aspecto que merece destaque sobre o quadro brasileiro é a distribuição destas figuras de proteção segundo as unidades federativas. Nesse sentido, nada menos que seis delas estão no Rio Grande do Sul (uma DO e cinco IP), seis em Minas Gerais (todas IP), quatro no Rio de Janeiro (três DO e uma IP), três no Espírito Santo (todas IP) e, em menor medida, nos demais estados do país.

\section{RESULTADOS E DISCUSSÃO}

$\mathrm{O}$ argumento central que inspira este artigo é no sentido de trazer à luz alguns dos mais importantes obstáculos a serem transpostos na consolidação de um regime brasileiro de qualidade para os produtos agroalimentares. Nesse sentido, destacamos aqui, ainda que brevemente, algumas das diferenças abissais que separam Europa e Brasil quando aludimos ao conceito de IG, bem como ao desenho institucional subjacente ao processo de solicitação e registro desse tipo de signo distintivo de mercado.

Sobre esse aspecto, destacamos que no velho continente a aprovação definitiva, que culmina com o registro de IGP ou DOP, pode durar meses ou anos e, em linhas gerais, trata-se de processo que deve ser levado a termo por uma associação promotora (de produtores e/ou elaboradores) que estabelece um caderno de normas a ser acolhido pela representação oficial (Ministério da Agricultura e/ou Abastecimento) do respectivo país europeu a que pertence. Em sendo aceito, há uma aprovação transitória enquanto o processo tramita na Comissão Europeia de Agricultura e Desenvolvimento, o qual, se admitido, conquista finalmente o registro

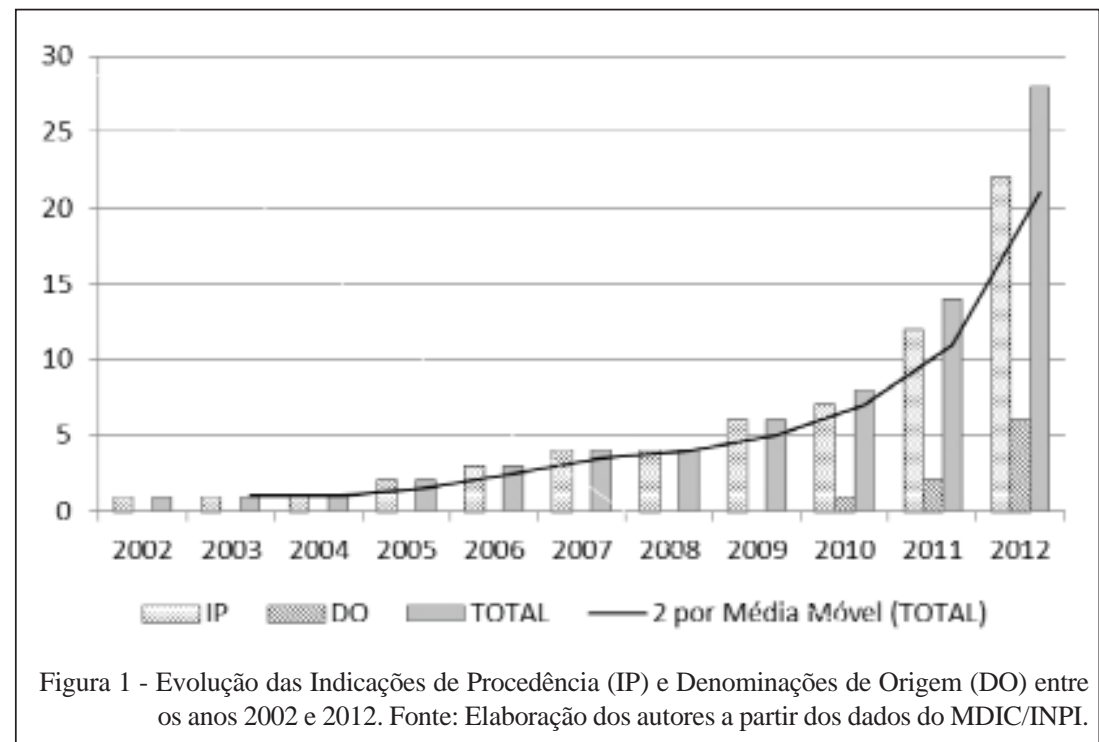

Ciência Rural, v.43, n.9, set, 2013. 
definitivo que lhe permite o uso de etiqueta específica identificadora da marca europeia de qualidade diferenciada, seja ela uma DOP ou IGP.

No âmbito de cada país europeu, são as autoridades públicas ou organismos privados de certificação os agentes responsáveis por controlar o estrito cumprimento do que estabelece o caderno de normas. Vale a pena frisar que essas empresas privadas (certificadoras) também certificam outros regimes de qualidade, como é o caso da produção ecológica e/ou da produção integrada.

Outro aspecto interessante, que merece destaque, nessa alusão à mecânica institucional que orienta a criação e funcionamento das IG nos países da União Europeia, diz respeito ao fato de que as empresas certificadoras estão igualmente subordinadas a regimes de controle e fiscalização. No caso da Espanha, tem-se a "Entidad Nacional de Acreditación”, um órgão subvencionado e tutelado pelo Ministério de Ciência e Tecnologia daquele país, o qual, literalmente, e com perdão da redundância, certifica as certificadoras.

No caso brasileiro, não obstante o espetacular incremento no número de IG aceitas pelo INPI ou em fase de registro, aludido anteriormente, não são poucos os obstáculos a serem transpostos para consolidar um sistema de certificações que valorize, concretamente, a produção agroalimentar e os artigos com qualidade diferenciada. Parte-se aqui da premissa de que não se trata de uma questão irrelevante. Mais do que nunca, vivemos hoje sob o signo de um movimento mais amplo - o quality turn que impera sobre o mundo da alimentação em geral, mormente no âmbito das cadeias agroalimentares, em toda sua diversidade (GOODMAN, 2003).

O estudo sobre as experiências de IG existentes no Brasil revela, entre outros aspectos, uma fragilidade institucional importante. Figura em destaque a falta de entendimento com respeito à atuação dos diferentes ministérios frente à importância e aos objetivos que perseguem esse tipo de dispositivo e de outros sinais distintivos. Além disso, não é clara a atribuição correspondente aos distintos órgãos envolvidos (EMBRAPA, SEBRAE, universidades, organizações não governamentais, etc.), cujas posições, não raras vezes, mostram-se conflitantes e incapazes de construir alianças entre os distintos atores implicados. A fragilidade do sistema de IG do Brasil é patente, se temos em mente que, no velho continente, nada menos que $50 \%$ das despesas dos Conselhos Reguladores, referentes à promoção e divulgação dos seus produtos, são subvencionadas pela própria UE, não sendo, portanto, obra do acaso que a Europa conta, atualmente, com um número muito expressivo de produtos com indicação geográfica. Some-se a isso o apoio financeiro (direto ou indireto) concedido a essas iniciativas através de programas de desenvolvimento territorial (especialmente o Programa LEADER) e da própria Política Agrária Comunitária (PAC).

$\mathrm{O}$ que aqui se quer sublinhar é que a recente expansão no número de experiências de diferenciação constatada em nosso país não tem sido capaz de engendrar mudanças, que consideramos imprescindíveis, para estabilizar um sistema que, atualmente, mostra-se como extremamente frágil e carente de coordenação.

Evocamos, novamente, o contraponto com a experiência europeia para mostrar que, no Brasil, não contamos com um órgão que certifique a atuação dos conselhos reguladores. No capítulo final de publicação do SEBRAE, Suzana KAKUTA (2006) menciona a existência de quatro níveis de controle numa IG. O primeiro deles é exercido pelos próprios produtores; o segundo, através do respectivo Conselho Regulador. O terceiro deles é opcional e, quando existente, é realizado periodicamente por um organismo de certificação (terceira parte). No último nível, constam aqueles organismos que objetivam o cumprimento dos requisitos compulsórios (como no caso do Sistema de Inspeção Federal ou outros regulamentos técnicos específicos) e a outorga da concessão da IG. O cumprimento desse conjunto de requisitos (voluntários e compulsórios) é o que garante a permanência da outorga de concessão de IG conferida pelo INPI. Mas, ao fim e ao cabo, de que mecanismos dispomos atualmente para exercer esse controle por parte do Estado, em que pese a fragmentação de sua atuação e a natureza eminentemente setorial que acompanha o papel das agências de regulação?

$\mathrm{Na}$ atual conjuntura, o registro no INPI acaba por ser o ponto de chegada de um processo extremamente complexo de concertação social, quando, em verdade, deveria ser visto como um ponto de partida para fomentar novas alianças entre os mais diversos setores (turismo, serviços, etc.), via construção de um discurso que fortaleça a identidade e valorize os ativos tangíveis e intangíveis de um determinado território. Nos raros casos em que isso ocorre, tais iniciativas resultam de ações voluntárias e, invariavelmente, desarticuladas entre si.

Por fim, mas não menos importante, emerge com força um problema que remete à própria concepção de IG adotada em nosso país, a qual é vista como refém do que NIEDERLE (2011) define como 
"perspectiva evolucionista”, a qual concebe IP e DO enquanto etapas distintas de um mesmo processo de qualificação, quando, em verdade, representam, ao menos juridicamente, instrumentos diferenciados de proteção de bens imateriais.

Na prática, a IP tem sido vista como uma forma de proteção mais flexível que a DO, o que, no nosso entendimento, não é certo, porque se trata de proteger aspectos de propriedade imaterial diferenciados: reputação ou características qualitativas específicas. No contato que realizamos com vitivinicultores do Vale dos Vinhedos, essa visão evolucionista foi evidenciada. A maior parte dos membros dos Conselhos Reguladores enxerga a DO como um estágio superior ao da IP, por ser aquela mais restritiva em relação a uma série de quesitos previstos no caderno de normas, especialmente do ponto de vista da procedência da uva utilizada na elaboração do vinho (100\% do próprio território, enquanto no caso da IP é 85\%), cultivares de uva permitidas, etc. Nesse sentido, havendo sido criada a DO, qual o tratamento a ser dado à IP? Em sendo mantida, não seria ela vista pelos consumidores como uma figura de proteção aderida a um produto de qualidade inferior, relativamente ao vinho classificado como DO?

Elaboramos esse trabalho a partir do reconhecimento acerca da importância dessas e de outras indagações para ampliar o debate em torno das possibilidades que nos brindam as IG para proteger a excelência dos produtos com identidade e, simultaneamente, fortalecer o desenvolvimento dos territórios. Se nossas considerações contribuem para que ocorra essa reflexão, daremos por cumpridos alguns dos objetivos que marcaram esse estudo.

\section{AGRADECIMENTOS}

Os autores agradecem à Fundação de Amparo à Pesquisa do Estado do Rio Grande do Sul (FAPERGS).

\section{REFERÊNCIAS}

AGUILAR CRIADO, E. et al. Culturas, políticas de desarrollo y turismo rural en el ámbito de la globalización. Horizontes Antropológicos, v.9, n.20, p.161-183, 2003.
CONTRERAS, J. Alimentación y sociedad. Sociología del consumo alimentario en España. In: GÓMEZ, C.; GONZÁLEZ, J.J. Agricultura y sociedad en el cambio de siglo. Madrid: McGraw-Hill, 2002. p.297-332.

DÍAZ-MÉNDEZ, C. et al. Hábitos alimentarios, consumo y salud: perspectivas y retos en los análisis sociales de la alimentación contemporánea. Revista Española de Sociología, n.12, p.105109, 2009.

ENAC (ENTIDAD NACIONAL DE ACREDITACIÓN). Sectores. Acessado em 25 jul. 2012. Online. Disponível em: <http://www. enac.es/web/enac/sectores>.

GOODMAN, D. The quality 'turn' and alternative food practices: reflections and agenda. Journal of Rural Studies, v.19, n.1, p.1-7, 2003.

GRANDO, M.Z. Pequena agricultura em crise: o caso da colônia francesa no Rio Grande do Sul. Porto Alegre: FEE, 1990. 209 p.

HERVIEU, B. Los campos del futuro. Madrid: MAPA, 1996. $195 \mathrm{p}$.

KAKUTA, S. Guia de respostas sobre indicações geográficas. In: LAGES, V. et al. Valorização de produtos com diferencial de qualidade e identidade: indicações geográficas e certificações para a competitividade nos negócios. 2.ed. Brasília: SEBRAE, 2006. p.247-274.

LANGREO NAVARRO, A. La agricultura contractual. Madrid: COAG, 1988. 141 p.

LOZANO, C. Canales cortos de comercialización y consumo social de productos ecológicos en Andalucía. In: CONGReSO ESPAÑOL DE SOCIOLOGÍA DE LA ALIMENTACIÓN, 2009, Gijón. Anais... Gijón: FES, 2009. 1 CD.

MUCHNIK, J. Identidad territorial y calidad de los alimentos: procesos de calificación y competencias de los consumidores. Agroalimentaria, n.22, p.89-98, 2006.

NIEDERLE, P.A. Compromissos para a qualidade: projetos de indicação geográfica para vinhos no Brasil e na França. 2011. 263f. Tese (Doutorado em Ciências Sociais) - Programa de Pósgraduação em Ciências Sociais em Desenvolvimento, Agricultura e Sociedade, Universidade Federal Rural do Rio de Janeiro, RJ.

NYGARD, B.; STORSTAD, O. De-globalization of food markets? Consumer perceptions of safe food: the case of Norway. Sociologia Ruralis, v.38, n.1, p.35-53, 1988.

SCHMITT, B.H. Experimental marketing. New York: The Free, 1999. 280 p. 